\title{
Seroprevalence and Carrier Status for Leptospirosis in Cattle and Goats in Andaman Island, India
}

Sameer Sharma ${ }^{1 *}$, Vijayachari $P^{1,2}$, Sugunan AP ${ }^{1}$, Subarna Roy ${ }^{2}$ and Kalimuthusamy Natarajaseenivasan ${ }^{3}$

${ }^{1}$ Regional Medical Research Centre (ICMR), Port Blair, Andaman \& Nicobar Islands, India

${ }^{2}$ Regional Medical Research Centre (ICMR), Belgaun, Karnataka, India

${ }^{3}$ Department of Microbiology and Bharathidasan Biomedical Diagnostic Centre, School of Life Sciences, Bharathidasan University, Tiruchirappalli, India

\begin{abstract}
Leptospirosis is endemic to the Andaman Islands and is emerging as an important public health problem in many other parts of India. The ecology of the Andaman Islands is ideal for the disease to remain as an endemic in the warm and humid environment within the rodent population as reservoirs, wild and domestic animals as carriers and affecting humans as incidental hosts. Furthermore, there is a lack of studies regarding the serological and genetic affinities of leptospires infecting humans and animals in Andaman region. A modest study was undertaken to understand the leptospiral carrier state and seroprevalence among animals slaughtered in an abattoir in the Andaman. Serum samples were collected from 184 cattle and 202 goats slaughtered in the abattoir during a two-year period and tested for the presence of leptospiral antibodies. Isolation was also attempted from kidney samples of each of these animals. High seroprevalence of $37 \%$ was observed in cattle and $29 \%$ in goats slaughtered. Since animals brought from different parts of the Andaman Islands showed Icterohaemorrhagiae, Grippotyphosa and Hebdomadis as the commonest reacting serogroups that are also the commonest among human cases and these animals might have been playing an important role in spreading the disease. Four leptospires were isolated from cattle, belonging to the serogroup Icterohaemorrhagiae. The study highlights the importance of a wide project involving animals and the environment for understanding the transmission dynamics of leptospirosis in the Islands which will help in devising of control and intervention strategies.
\end{abstract}

Keywords: Leptospirosis; Carrier state; Abattoir; Seroprevalence; Animal

\section{Introduction}

Leptospirosis is one of the most widespread zoonosis in the world [1]. It is caused by the pathogenic members of the spirochete belonging to the genus Leptospira. Domestic and wild animals infected with the disease harbor these organisms and excrete them through their urine into the environment and when humans come in accidental contact with such contaminated environment, they acquire the infection through broken or sodden skin. Some large animals like cattle are known to harbor leptospires in their kidneys for few days to even years thereby continuing to contaminate the environment and serving as source of infection for human beings. Rodents are considered to be the reservoir host and they shed the organism life-long through their urine. In humans, the disease presents itself in the form of mild flu-like illness to severe forms with multi-organ involvement with or without haemoptysis [2].

Leptospirosis is reemerging as an important public health problem in the world especially in developing countries including India. In India recently there has been an upsurge of the disease in certain states like Tamil Nadu, Kerala, Gujarat, and Maharashtra [35]. Andaman \& Nicobar Islands in India is where the first authentic report of leptospirosis came from, way back in 1929 when Taylor and Goyle isolated leptospires from patients with Weil's disease [6]. The disease remains endemic to these islands and often occurs as postmonsoon outbreaks of febrile illness with haemorrhagic tendencies [7]. Sero-epidemiological and follow-up studies carried out in different population groups of these islands has shown Grippotyphosa, and Pomona as the common serogroups, [7] while genetic studies revealed the predominance of a particular clone.

Microscopic agglutination test (MAT) is considered to be the gold standard serological test for the diagnosis of leptospirosis. But this test does not differentiate IgM and IgG antibodies but detects mainly IgM and IgM demonstrate recent infection. Other common draw backs are maintenance of battery of live circulating serovar, interpretation of test results and requires well equipped laboratory for the test. Other test like ELISA which detects both IgM and IgG. After infection when IgM peaks and stays for longer period of time IgG appears. This test is easy to perform and is economical.

Infection with serovars of leptospires, these animals poses risk to other livestocks, animal handlers, butchers and other abattoir workers. So, this study was planned to understand the infecting serovar in an abattoir and the role these animals as potential zoonotic importance in causing the disease to human being. This will also give an idea about the transmission dynamics of the disease leptospirosis.

\section{Materials and Methods}

\section{Samples}

The project has been given clearance by the institutional ethical committee. A total of 184 cattle blood and kidney tissues $(1-2 \mathrm{~cm})$ were collected from a Government owned abattoir situated at the village

*Corresponding author: Sameer Sharma, Regional Medical Research Centre (ICMR), Port Blair, Andaman \& Nicobar Islands, India, Tel: +91 3192 251158; Fax +91 3192 251043; E-mail: sameersharma2011@yahoo.co.in, pblicmr@sancharnet.in

Received September 09, 2014; Accepted November 26, 2014; Published November 28, 2014

Citation: Sharma S, Vijayachari P, Sugunan AP, Roy S, Kalimuthusamy N (2014) Seroprevalence and Carrier Status for Leptospirosis in Cattle and Goats in Andaman Island, India. J Veterinar Sci Technol 5: 205. doi:10.4172/2157 7579.1000205

Copyright: $\odot 2014$ Sharma S, et al. This is an open-access article distributed under the terms of the Creative Commons Attribution License, which permits unrestricted use, distribution, and reproduction in any medium, provided the original author and source are credited. 
Citation: Sharma S, Vijayachari P, Sugunan AP, Roy S, Kalimuthusamy N (2014) Seroprevalence and Carrier Status for Leptospirosis in Cattle and Goats in Andaman Island, India. J Veterinar Sci Technol 5: 205. doi:10.4172/2157-7579.1000205

Calicut $12 \mathrm{~km}$ from Port Blair city. All animals were adult male. Blood and kidney tissues were also collected from 202 goats slaughtered in two different slaughterhouses situated in Port Blair. All the animals were male and were brought from different parts of the Andaman Islands (Figure 1). All animals slaughtered were certified for the human consumption by the local veterinary authorities. The samples were collected during a period of two years between September 2003 and September 2005. These animals were brought from different areas of Port Blair. Animals were slaughtered during Friday, Saturday and Sunday. Based on the abattoir records, 8 to 10 cattles were slaughtered each week with an average of 32 to 40 cattles each month. Eighteen to twenty goats are slaughtered every week.

\section{Culture and isolation}

All the kidneys obtained were transferred aseptically in a zipped plastic sack and sealed immediately after collection and transported to the laboratory in an ice filled container $\left(4^{\circ} \mathrm{C}\right)$ immediately. It took 20 minutes to bring the specimen to the laboratory. In the laboratory, the cortex portion of kidneys were cut cross-sectionally and 1-2 cm of crushed dip cortex portion" above the medulla was inoculated into

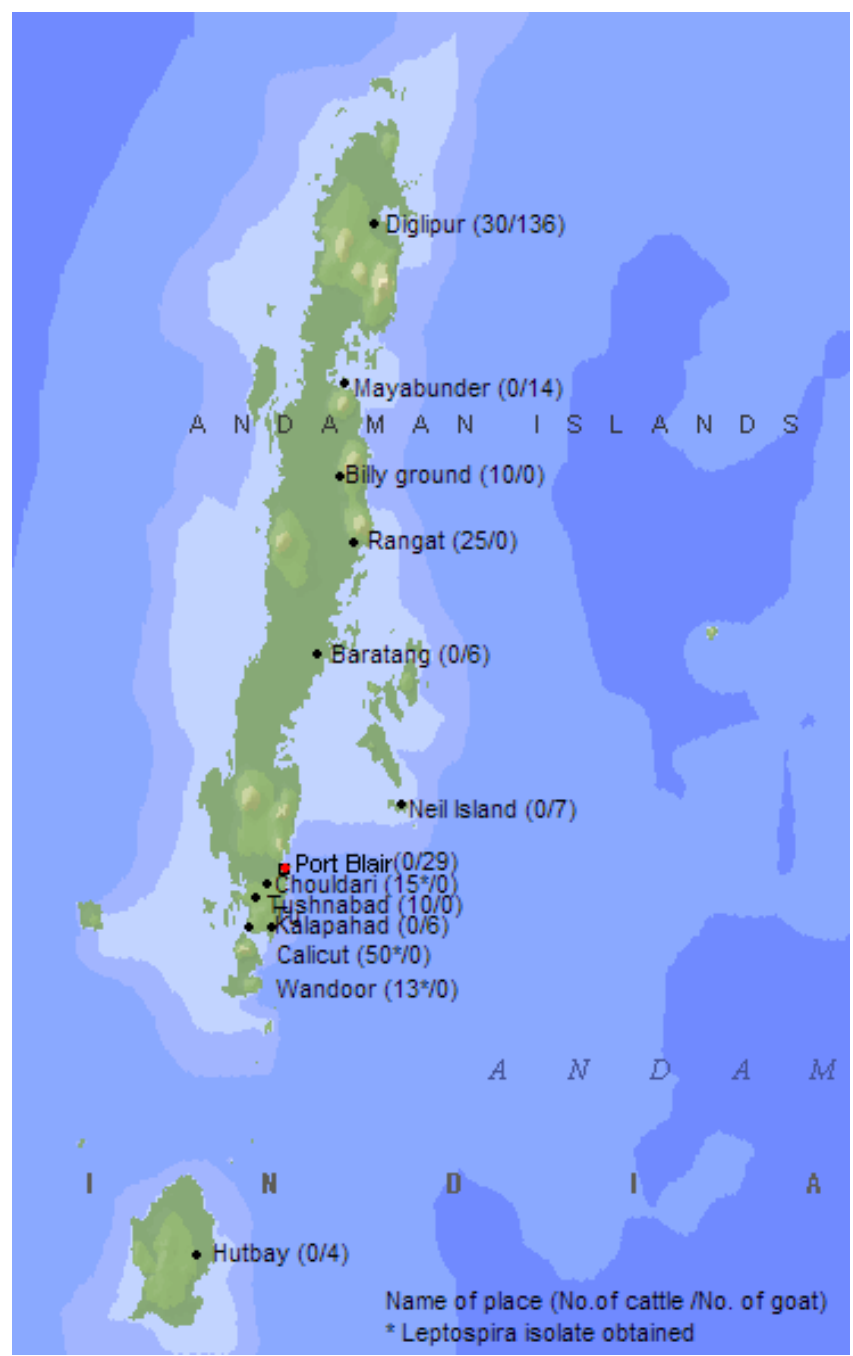

Figure 1: Places from where cattles/goats were brought for slaughter. Place name is followed by number of cattle brought / number of goats brought in parenthesis. selective EMJH semisolid medium containing 2\% rabbit serum and 100 $\mu \mathrm{l} / \mathrm{ml}$ of 5 -fluorouracil (Sigma, India). These cultures were examined under dark field microscope (Olympus CH 40 RF 200, Japan) for growth of leptospires weekly for months.

\section{Serology}

Serum was separated from blood samples and stored at $-70^{\circ} \mathrm{C}$. Serum samples were tested for the presence of anti-leptospiral antibodies using microscopic agglutination test (MAT) following standard procedures [8]. A battery of reference strains belonging to twelve serogroups [9] common in the Andaman Islands and in mainland India were included in the MAT as antigens (Table 1).

Titres of 80 or more against any of the serovars in MAT were considered as evidence of leptospiral infection $[1,10]$. Serogroup status of the isolates was obtained by MAT using group sera as well as panels of mouse polyclonal antibodies (mAbs) belonging to serogroups Canicola, Grippotyphosa, Hebdomadis, Icterohaemorrhagiae, Javanica, Mini, Pyrogenes, Shermani and Sarmin following the procedure described earlier [3]. These polyclonal were obtained from KIT, Amsterdam, The Netherlands. For determination of the serovar status of isolates by MAT, a panel of serovar specific monoclonal antibodies (70 7-11, 70 13-1 and 82 2-3) representative of the serogroup Icterohaemorrhagiae were obtained from the Royal Tropical Institute, KIT, Amsterdam, The Netherlands.

\section{Genomic DNA isolation}

DNA was extracted following standard procedure [2] from 12 leptospiral reference strains circumscribing 5 genomospecies (Table 2). In addition, DNA was obtained from the isolates recovered from the slaughtered animals during the study.

\begin{tabular}{|l|c|c|c|}
\hline SI. & Serogroup & Serovar & Strain \\
\hline 1 & Australis & Australis & Ballico \\
\hline 2 & Autumnalis & Autumnalis & Rachmati \\
\hline 3 & Bataviae & Bataviae & Swart \\
\hline 4 & Canicola & Canicola & Hond Utrecht IV \\
\hline 5 & Grippotyphosa & Grippotyphosa & Moskva V \\
\hline 6 & Icterohaemorrhagiae & Icterrohaemorrhagiae & RGA \\
\hline 7 & Javanica & Poi & Poi \\
\hline 8 & Ballum & Ballum & Mus127 \\
\hline 9 & Pomona & Pomona & Pomona \\
\hline 10 & Sejroe & Hardjo & Hardjoprajitno \\
\hline 11 & Cynopteri & Cynopteri & 3522C \\
\hline 12 & Pyrogenes & Pyrogenes & Salinem \\
\hline
\end{tabular}

Table 1: List of reference strains used in the panel of MAT antigens.

\begin{tabular}{|l|c|c|c|}
\hline SI. & Genomospecies & Serovar & Strain \\
\hline 1 & L.interrogans & Australis & Ballico \\
\hline 2 & L.interrogans & Rachmati & Rachmat \\
\hline 3 & L.interrogans & Icterohaemorrhagiae & RGA \\
\hline 4 & L. kirschneri & Ratnapura & Wumalasena \\
\hline 5 & L.kirschneri & Vanderhoedeni & Kipod179 \\
\hline 6 & L.kirschneri & Cynopteri & 3522C \\
\hline 7 & L.borgpetersenii & Tarassovi & Perepelitsin \\
\hline 8 & L.borgpetersenii & Mini & Sari \\
\hline 9 & L.santarosai & Canalzonae & CZ188 \\
\hline 10 & L.santarosai & Weaveri & CZ390 \\
\hline 11 & L.noguchii & Panama & CZ214K \\
\hline 12 & L.noguchii & Louisiana & LSU1945 \\
\hline
\end{tabular}

Table 2: List of reference strains used for comparative genetic analysis. 
Citation: Sharma S, Vijayachari P, Sugunan AP, Roy S, Kalimuthusamy N (2014) Seroprevalence and Carrier Status for Leptospirosis in Cattle and Goats in Andaman Island, India. J Veterinar Sci Technol 5: 205. doi:10.4172/2157-7579.1000205

\section{Fingerprinting by Random Amplified Polymorphic DNA (RAPD) assay}

RAPD fingerprinting assay was performed following [5]. The PCR reactions were carried out in 50 $\mu$ l total volume consisting of $50 \mathrm{ng}$ of leptospiral chromosomal DNA, $10 \mathrm{mM}$ Tris- $\mathrm{HCl}$ (pH9.0), $50 \mathrm{mM} \mathrm{KCl}, 4 \mathrm{mM} \mathrm{MgCl}_{2}$, each of the four deoxynucleotide triphosphates at a concentration of $0.1 \mathrm{mM}$, 300pM of primers B11 (CCGGAAGAAGGGGCGCCAT) and B12 (CGATTTAGAAGGACTTGCACAC) (Sigma Aldrich, USA) and 0.5 U of Taq DNA polymerase (Sigma Aldrich, USA). PCR was carried out in DNA Engine PTC 200 thermal cycler (MJ Research Peltier Thermal cycler, PTC 200, USA). The first two cycles consisted of a denaturation at $95^{\circ} \mathrm{C}$ for $5 \mathrm{~min}$, annealing of primers for $5 \mathrm{~min}$ at $40^{\circ} \mathrm{C}$, and extension for $5 \mathrm{~min}$ at $72^{\circ} \mathrm{C}$. The subsequent 35 cycles consisted of denaturation for $1 \mathrm{~min} 95^{\circ} \mathrm{C}$, annealing of primers for $1 \mathrm{~min}$ at $60^{\circ} \mathrm{C}$, and extension at $72^{\circ} \mathrm{C}$ for $3 \mathrm{~min}$, with a final extension step at $72^{\circ} \mathrm{C}$ for $10 \mathrm{~min}$ during the last cycle. PCR products were resolved in $1 \%$ agarose gels in TAE buffer containing ethidium bromide $0.5 \mu \mathrm{g} / \mathrm{ml}$ and revealed under UV illumination and documented using Bio-Rad gel documentation system (Italy). Phylogenetic tree (UPGAMA with $2.0 \%$ tolerance) was constructed using Bio-Gene analysis software (Vilber Lourmat, BP 66-Torcy Z. I, Sud, F-77202, Marme-la-Vallee, Cedex 1, France). Distilled water was taken as negative control and known leptospiral DNA was taken as positive control.

\section{Results}

Leptospiral antibodies were detected in 63 samples (34\%) out of the 184 serum samples obtained from cattle. Out of the 202 serum samples obtained from goats, 58 samples (29\%) presented reactivity (titres $\geq 80$ ).

Among the samples that showed leptospiral antibodies in cattle, Icterohaemorrhagiae, Hebdomadis and Grippotyphosa were found to be the commonest serogroups ( $22.2 \%$ each) followed by Australis
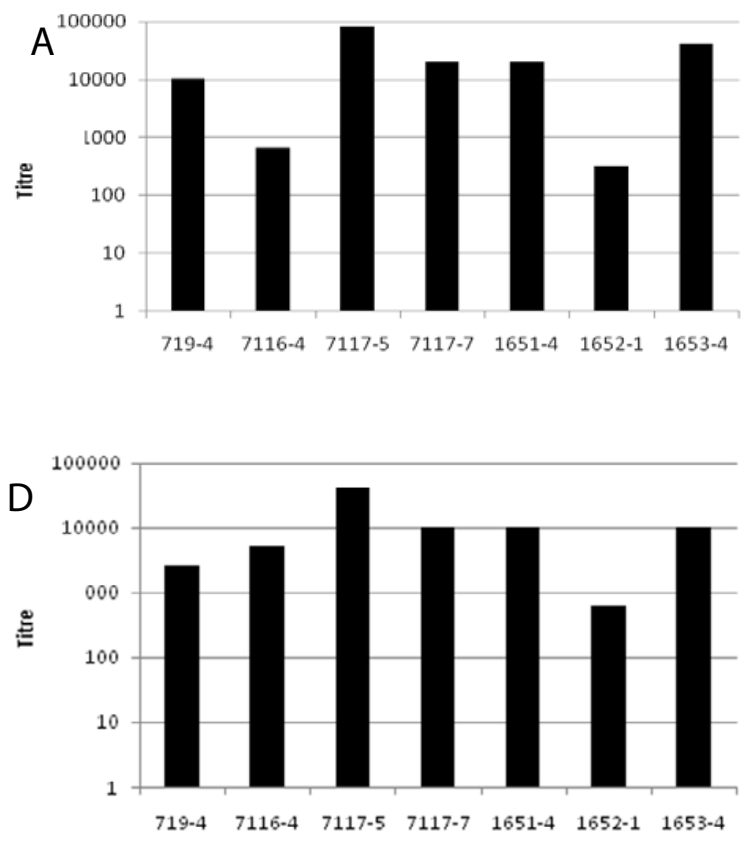

Monoclonal antibodies
(9.5\%), Sejroe (7.9\%), Autumnalis (4.7\%), Pomona (4.7\%), Ballum (3.1\%) and Pyrogenes (3.1\%). Majority of the sero-reactive samples presented titres of $80(34 \%)$. High titres 640 were observed against Grippotyphosa and Hebdomadis.

In goats highest seroreactivity was observed against Icterohaemorrhagiae (22.4\%) followed by Grippotyphosa (15.5\%), Hebdomadis (13.8\%), Sejroe (10.3\%), Pomona (8.6\%), Australis (5.2\%), Autumnalis and Ballum (3.4\%, each). Also in this species, titres of 80 were the most frequent (29\%).

Four leptospires were isolated from kidney samples of the slaughtered cattle were from different areas of Andaman Islands. Serological characterization carried out employing group sera revealed that all the isolates belonged to the serogroup Icterohaemorrhagiae, and also servar Icterohaemorrhagiae (Figure 2).

RAPD-PCR of all the four isolates obtained from cattle kidney samples revealed that all the four isolates were genetically similar Phylogenetic analysis by comparison of the fingerprinting patterns of these isolates with reference strains circumscribing five different genomo-species revealed that these isolates were genetically closest to Leptospira interrogans (Figures 3 and 4).

\section{Discussion}

Agricultural workers, forest workers and animal handlers have been identified as one of the high risk groups [11-13] for acquiring leptospirosis on the rural environment. A holistic knowledge of the transmission dynamics of the disease is required to formulate intervention strategies for a particular geographical area. The hot and humid climate, large forest cover, heavy rainfall and presence of wild and domestic animals and rodents provide Andaman Islands with the ideal ecology for leptospiral transmission [9]. Knowledge of the leptospiral carrier states serological and genetic affinities of the leptospires circulating in the different animals, rodents, environment
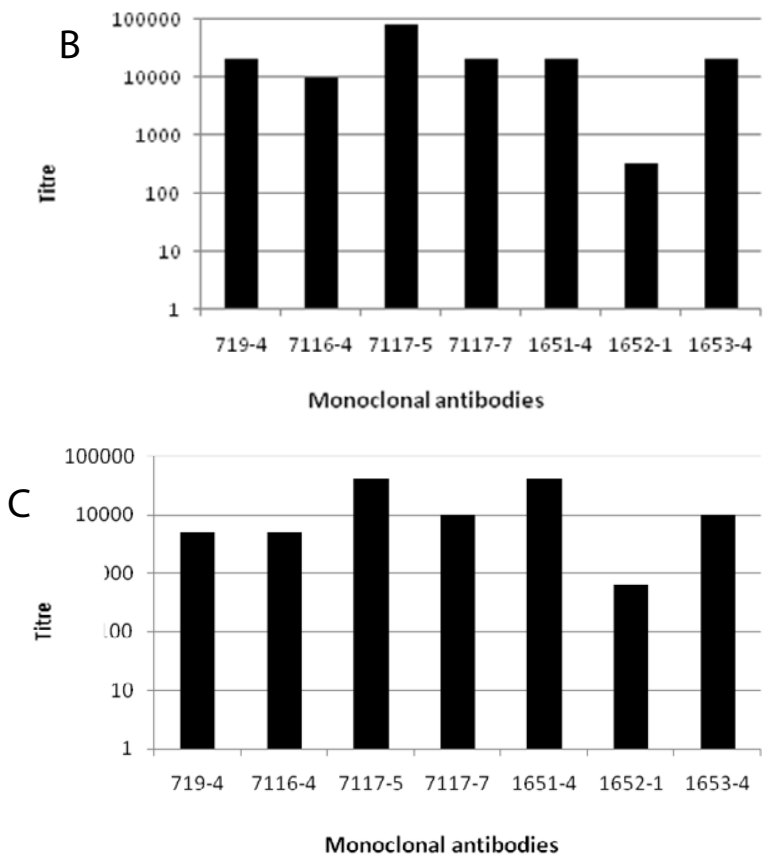

Figure 2: Antigenic properties of the different isolates with monoclonal antibodies. 
Citation: Sharma S, Vijayachari P, Sugunan AP, Roy S, Kalimuthusamy N (2014) Seroprevalence and Carrier Status for Leptospirosis in Cattle and Goats in Andaman Island, India. J Veterinar Sci Technol 5: 205. doi:10.4172/2157-7579.1000205

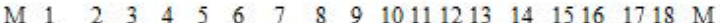

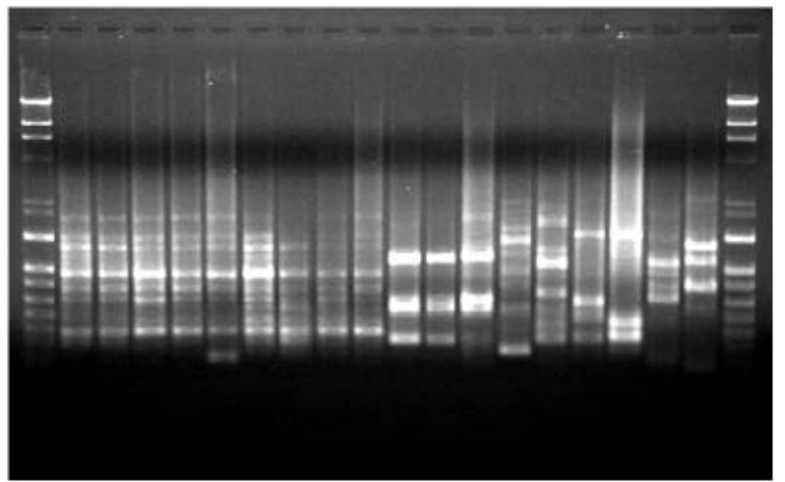

M= Lamda DNA Hind III/puc18/Sau 3A-1puc18/Taq digest (Bangalore Genie, Bangalore, India).

Figure 3: RAPD fingerprints of the 4 isolates obtained (Lanes 1-4) along with12 reference strains of leptospires (Lanes 5-18) circumscribing 5 genospecies (sequentially as in Table 2).

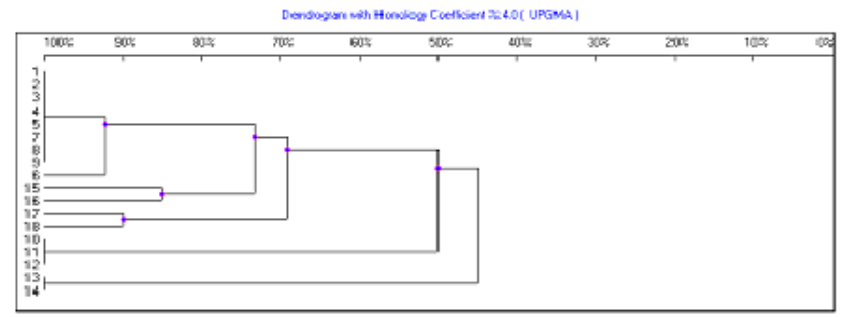

Figure 4: Dendogram of homology between the 4 isolates obtained (Lanes 1-4) along with12 reference strains of leptospires (Lanes 5-18) circumscribing 5 genospecies.

and humans can help in the process. It has been shown that the serogroups Grippotyphosa, Icterohaemorrhagiae and Hebdomadis are commons in the Andaman Islands [8,9]. In a particular study, it has also been shown that isolates obtained from human cases of leptospirosis belonged to the genospecies L. interrogans. Although much information is available on the serological and molecular genetic characterization of leptospires infecting humans, the same is not available for animals or in the environment.

In the present study we found high seroprevalence in cattle (34\%) and goats (29\%). The commonest serovars found were Icterohaemorrhagiae, Hebdomadis and Grippotyphosa and is in agreement with Sharma et al., [9] on the apparently healthy domestic animals. Serovar Sejroe is traditionally known to be associated with cattle leptospirosis [14] but in our study, its prevalence was low at $8 \%$ of the total positives. Icterohaemorrhagiae, Grippotyphosa and Hebdomadis were also found to be the commonest serogroups detected in goats. The study indicates that the serogroups that commonly infect humans are the same that are prevalent in cattle and goats in the Andaman Islands.

The slaughtered animals under study were brought from different regions/islands within the Andaman group of islands and no regionwise specificity for serogroup or genotype was observed. However, the regions where these animals were brought from are places where occurrence of leptospirosis is common and the animals could be playing an important role in spreading infection to humans in these areas.

Two of the four isolates were made from bulls that showed titres of 80 against the serovar Icterohaemorrhagiae and the other two were considered seronegative.

The fact that all the isolates showed the same genetic pattern suggests that the same strain may be circulating in different animals and at different locations in the Andaman Islands. The genetic affinity of these isolates to L. interrogans suggests that this particular species, like in the human cases might be the commonest genomospecies of Leptospira in slaughtered animals.

The culture positives confirm the circulating serovar in the Islands. There are isolates from humans and the present isolates belong to the same serogroup and could be playing a major role in leptospirosis infection among human population.

\section{Acknowledgement}

Authors sincerely thank Department of Animal Husbandry, Port Blair for their help in collecting samples from slaughter house and also for the necessary data about the animals. The authors are thankful to all the technicians and supporting staff for their constant help. Authors sincerely thank Royal Tropical Institute, KIT, Amsterdam, The Netherlands for supplying monoclonal antibodies for the present study.

\section{References}

1. Levett PN (2001) Leptospirosis. Clin Microbiol Rev 14: 296-326.

2. Faine S (1999) Leptospira and leptospirosis, 2nd Edition. Medsci. Melbourne, Vic. Australia.

3. Vijayachari P, Sehgal SC, Goris MG, Terpstra WJ, Hartskeerl RA (2003) Leptospira interrogans serovar Valbuzzi: a cause of severe pulmonary haemorrhages in the Andaman Islands. J Med Microbiol 52: 913-918.

4. Brown PD, Levett PN (1997) Differentiation of Leptospira species and serovars by PCR-restriction endonuclease analysis, arbitrarily primed PCR and lowstringency PCR. J Med Microbiol 46: 173-181.

5. Ramadass $P$, Meerarani $S$, Venkatesha MD, Senthilkumar A, Nachimuthu K (1997) Characterization of leptospiral serovars by randomly amplified polymorphic DNA fingerprinting. Int J Syst Bacteriol 47: 575-576.

6. Taylor J, Goyle AN (1931) Leptospirosis in Andamans. Indian Medical Research Memoirs, Supplementary series to the Indian Journal of Medical Research. Indian J Med Res; Memoir, 20: 55-56.

7. Vijayachari P (2004) Leptospirosis among school children of the Andaman \& Nicobar Islands, India: low levels of morbidity and mortality among pre-exposed children during an epidemic. Epidemiol Infect. 132: 115-120.

8. Singh SS, Vijayachari $P$, Sinha A, Sugunan AP, Rasheed MA, et al. (1999) Clinico-epidemiological study of hospitalized cases of severe leptospirosis. Indian J Med Res 109: 94-99.

9. Sharma S, Vijayachari P, Sugunan AP, Sehgal SC (2003) Leptospiral carrier state and seroprevalence among animal population-a cross sectional sample survey in Andaman \& Nicobar Islands. Epidemiol Infection, 131: 985-989.

10. Wolff JW (1954) The laboratory diagnosis of leptospirosis. Illinions, Charles C Thomas, 31-51.

11. Sehgal SC, Murhekar MV, Sugunan AP (1995) Outbreak of leptospirosis with pulmonary involvement in north Andaman. Indian J Med Res 102: 9-12.

12. Murhekar MV, Sugunan AP, Vijayachari P, Sharma S, Sehgal SC (1998) Risk factors in the transmission of leptospiral infection. Indian J Med Res 107: 218223.

13. Sharma S, Paluru V, Attayoor PS, Kalimuthusamy N, Manoj VM, et al. (2006) Seroprevalence of Leptospirosis among Jarwas-a Hunter-gatherer primitive negrito tribe of Andaman and Nicobar Islands, India. Res J Microbiology, 1 95-100.

14. Prescott JF, Miller RB, Nicholson VM (1987) Isolation of Leptospira hardjo from kidneys of Ontario cattle at slaughter. Can J Vet Res 51: 229-231. 